\title{
EL FIN DE EUROPA (Y DE LO QUE NO ES EUROPA). MOTIVOS Y VERSIONES DEL FINAL SEGÚN RAFAEL SPREGELBURD ${ }^{1}$
}

\author{
María Fernanda Pinta \\ Consejo Nacional de Investigaciones Científicas y Técnicas, CONICET \\ Universidad Nacional de las Artes \\ Argentina \\ pintafernanda@gmail.com \\ Orcid: 0000-0002-3872-9484
}

Fecha de recepción: 04/06/202I| Fecha de aceptación: 01/07/2021

\begin{abstract}
Resumen: En las últimas décadas, las catástrofes y complejidades de la historia asoman en el teatro de Rafael Spregelburd no solo en sus tematizaciones, sino también en exploraciones intermediales, seriadas y de larga duración que buscan movilizar, a nuestro entender, un pensamiento y una práctica acerca del lugar de la imaginación artística (y política) en la actualidad. Opera, igualmente, con el reciclaje de múltiples materiales y una revisión crítica sobre la ficción, la realidad y el tiempo que lo conectan con una manera de entender la historia en tanto trastornada ("preposterous history", en Bal). El presente trabajo busca analizar su proyecto más reciente, El fin de Europa, escrito entre 2012 y 20I7, bajo la siguiente premisa: un teatro en tiempos de crisis, calamidades y finales procura desmontar los relatos del fin haciendo ver que ese punto que marca la eclosión no es tanto un cierre, sino una posibilidad de entender y habitar el mundo de otra forma, aun cuando todavía no sepamos cómo hacerlo.
\end{abstract}

Palabras clave: El fin de Europa; Rafael Spregelburd; teatro argentino; serie teatral; larga duración.

The end of Europe (and of what is not Europe). Motifs and Versions of the Ending According to Rafael Spregelburd

Abstract: In the last decades, catastrophes and complexities of history appear in Rafael Spregelburd's theater not only in its thematizations, but also in intermedial, serial and long-lasting explorations that seek to mobilize, to our understanding, a thought and a practice about the place of artistic (and political) imagination today. It also operates with

1 Mi agradecimiento a Rafael Spregelburd, por las conversaciones mantenidas a la distancia y el material (inédito) compartido para la realización de este trabajo. 
the recycling of multiple materials and a critical rework about fiction, reality and time that connect it with a way of understanding history as "preposterous history" (Bal). The present work seeks to analyze his most recent project, The End of Europe, written between 2012 and 2017, under the following premise: a theater in times of crisis, calamities and endings seeks to dismantle the stories of the end making it seem that the point that marks the hatching is not so much a closure, but a possibility to understand and inhabit the world in another way, even if we still do not know how to do it.

Keywords: The End of Europe; Rafael Spregelburd; argentine theatre; long-running; theatre series.

O fim da Europa (e do que não é Europa). Motivos e versôes do final segundo Rafael Spregelburd

Resumo: Nas últimas décadas, as catástrofes e complexidades da história assoman no teatro de Rafael Spregelburd não só em suas tematizações, mas também em explorações intermediárias, seriadas e de longa duração que procuram mobilizar, ao nosso entender, um pensamento e uma prática sobre o lugar da imaginação artística (e política) hoje. Opera, igualmente, com a reciclagem de múltiplos materiais e uma revisão crítica sobre aficção, a realidade e o tempo que o conectam com uma maneira de entender a história em tanto transtornada ("preposterous history", em Bal). 0 presente trabalho busca analisar seu projeto mais recente, $O$ fim da Europa, escrito entre 2012 e 2017, sob a seguinte premissa: um teatro em tempos de crise, calamidades e finais procura desmontar os relatos do fim fazendo ver que esse ponto que marca a eclosão não é tanto um fechamento, mas uma possibilidade de entender e habitar o mundo de outra forma, ainda quando não saibamos como fazê-lo.

Palavras-chave: $O$ fim da Europa; Rafael Spregelburd; teatro argentino; série teatral; longa duração.

Y aun así, Dios guardará silencio. / El mismo silencio que guardó cuando se extinguió el Tiranosaurios Rex, / cuando se hundió Atlantis, / cuando ardió la Biblioteca de Alejandría, / cuando Europa llegó a su fin². (Spregelburd Segunda parte 52-53)

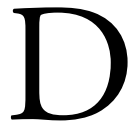
esde los ańos noventa Rafael Spregelburd es uno de los artistas más destacados de la escena teatral argentina. Dramaturgo, director, actor, traductor y docente, cuenta con más de treinta obras que han sido estrenadas en Argentina y en el exterior. Su trabajo, acompañado de traducciones a varios idiomas y premios, se desarrolla igualmente en el cine y la televisión, en la labor del ensayo crítico y, recientemente, en el campo de la narrativa con la publicación de Diarios del capitán Hipólito Parrilla (2018). En esta prolífica y diversa trayectoria, un conjunto de trabajos se caracteriza por abordar las catástrofes y complejidades de la cultura contemporánea y de la

2 Cada uno de estos fragmentos se repite en inglés, en italiano y en francés. 
historia en formatos que expanden la noción de obra hacia la de proyecto con características seriales y de larga duración.

Se trata de temas, procedimientos y formatos que, a nuestro entender, dan cuenta de un pensamiento y una práctica en torno al lugar de la imaginación artística (y política) en la actualidad. En 2012 Jorge Dubatti proponía una periodización para el trabajo de Spregelburd cuya última etapa, que comienza en 2001 y puede extenderse -creemos- hasta la actualidad, la presentaba del siguiente modo:

Spregelburd pone en práctica una nueva modalidad política de la sátira, variante de la distopía o la utopía negativa que denuncia una realidad degradada y, aniquilándola simbólicamente, permite ver que esa realidad ha sustituido a otra posible que no conocemos y deberíamos empezar a soñar. Es el teatro del grado cero de la utopía, a partir del que empezar a imaginar otra vez: Spregelburd no dice cómo debemos pensar, solo invita a pensar nuevamente porque es imprescindible. ("Rafael Spregelburd" 248)

El fin de Europa, gestado en el marco del laboratorio de la Ecole de Maîtres (Udine), presenta esta matriz productiva de forma elocuente:

Estábamos haciendo ese taller con actores franceses, belgas, italianos y portugueses cuando ocurrió ese episodio del intento de restauración del Ecce Homo de Borja, por Cecilia Giménez. Había empezado la crisis griega, yo a su vez estaba escribiendo Spam, se vivía un aire de apocalipsis que para mi era... muy vetusto. De vez en cuando Europa preanuncia su propio final, pero de modo de mantener los estatutos del poder intactos. Es una estrategia del terror. Yo trataba, como argentino y sobreviviente de una crisis permanente, de instar a la rebelión. A que comprendieran que el final podía tomarse en sorna. Y que siempre que se preanuncia el final, es porque quien ejerce ese preanuncio tiene preparado un reordenamiento a la manera de su conveniencia. Trabajamos sobre estas ideas con los actores y de ahí surgieron estas historias. (Halfon $s / \mathrm{n}$ )

De este modo, a partir de cierto clima de época y de las ideas en torno a la crisis y el final de Europa, el director con sus actores trama El fin de Europa que consta de ocho historias breves, interrelacionadas y, a la vez, lo suficientemente independientes como para que puedan ser montadas por separado. El texto, escrito entre 2012 y 2017 , está organizado en dos partes y cada una de ellas contiene a su vez cuatro piezas. Primera parte: "El fin de las fronteras", "El fin del arte", "El fin de la nobleza" y "El fin de la historia". Segunda parte: "El fin de la salud"; "El fin de la realidad"; "El fin de la familia" y "El fin de Europa"”. Sus distintas puestas en escena presentaron formatos que iban de la programación

3 El texto en su conjunto se encuentra inédito. El fin del arte ha sido publicado en: Dubatti, Jorge, editor. Panorama teatral. Buenos Aires, Interzona, 2013 y El fin de la salud ha sido publicado en formato eBook (Buenos Aires, Indie Libros, 2019). 
de una de las piezas, "El fin del arte", en el marco de una feria artística con varias repeticiones diarias y un espacio de debate posterior, hasta programas de dos noches o de una sola jornada de varias horas de duración ${ }^{4}$.

El presente trabajo busca analizar El fin de Europa haciendo foco en los sentidos que se abren desde la temporalidad y la narrativa del final. Al mismo tiempo, se propone reflexionar sobre sus principales características en tanto proyecto seriado de larga duración. Para ello nos centraremos en tres piezas: "El fin de la historia", "El fin del arte" y "El fin de Europa" que condensan, a nuestro entender, las ideas del dramaturgo en torno al tiempo, la historia, la catástrofe y la ficción de modo paradigmático.

\section{El síntoma del final}

Un buen modo de hablar del relato del final puede ser comenzar por el final. El fin de Europa cierra con la pieza "El fin de Europa" y esta a su vez termina con el fragmento que citamos al inicio: "Dios guardará silencio [...] El mismo que guardó [...] cuando Europa llegó a su fin". De este modo, en el cierre de la saga, el final de Europa ya ha tenido lugar en un tiempo indefinido y algo remoto, a juzgar por el resto de los eventos (reales y ficticios) igualmente acontecidos: la extinción de los dinosauros, el incendio de la Biblioteca de Alejandría, la desaparición de la Atlántida. El fin de Europa, entonces, puede ser parte de la historia o parte de la ficción. O bien, como sugiere la obra teatral en su conjunto, un poco ambas cosas. En tono de sátira, como el propio dramaturgo señalaba, la saga nos permite dudar de la idea del final. Más aún, no se trata tanto de que las instituciones, los valores y los paradigmas sobre los que tematiza El fin de Europa estén en crisis, en decadencia o hayan llegado a su fin (la monarquía, el arte, el sistema de salud, la familia, los principios de la realidad y de la historia, entre otros), sino que aún en el caso de que así sea, esa clausura no es necesariamente definitiva, absoluta. La clave aquí es pensar en finales que a su vez alumbran el inicio de otros comienzos (la mayoría de las veces indiscernible para los personajes y también para el lector/espectador).

Este cuestionamiento sobre la idea del final presenta, a nuestro entender, dos dimensiones. La primera, relacionada con aquella desconfianza que plantea Spregelburd sobre las narrativas del final y los sistemas de poder que las alimentan. Una segunda dimensión se ubica, en cambio, en la propia práctica poética y

4 Entre sus montajes, todos dirigidos por el propio Spregelburd, cuentan: El fin del arte (ArteBA, Buenos Aires, 2014 y Museo Castagnino + MACRO, 2017) y Tres finales (que incluía "El fin de la historia", "El fin de la realidad" y "El fin del arte", en el Teatro Argentino de La Plata y en el Teatro de la Ribera de Buenos Aires, en 2016 y 2017 respectivamente). En 2017 realizó el montaje de las ocho piezas conjuntas, mostrándose en Caen, Génova y Liege y al año siguiente se presentó en París (en estas ocasiones las piezas se montaron en dos jornadas y también en una versión integral de cuatro horas de duración). El fin de Europa conoció también otras direcciones escénicas, como es el caso del montaje que hizo Felipe Hirsch en San Pablo en 2019, al que llamó FIM y donde se mostraron las cuatro piezas de la primera parte. 
atañe, más precisamente, al modo en que el autor entiende la escritura dramática contemporánea. Aquí nos ocuparemos de esta segunda dimensión del problema que, en la propuesta de Spregelburd, pone a funcionar un pensamiento en torno a la estructura de la ficción y la lógica compleja de la realidad.

Un ensayo que Spregelburd publica en 2006, "Guía rápida para dramaturgos cazadores de catástrofes”, da cuenta de las ideas centrales: el trabajo sobre la ficción y el teatro hoy se resumen en una pregunta que formula del siguiente modo: ¿cuál es el espíritu del hombre de nuestro tiempo y, por ende, ¿cómo debemos representarlo? ( $\mathrm{s} / \mathrm{n})$. La respuesta está en cuestionar la naturaleza del tiempo, en preguntarse por los modelos (de la ficción, pero también de las ciencias) que rigen las relaciones de causas y efectos. El caso de la dramaturgia de William Shakespeare resulta un ejemplo: el plan de Julieta es perfecto, dice Spregelburd, pero falla. ¿Por qué falla? ¿Por qué la carta no llega a tiempo a Romeo? Shakespeare no lo explica. Así, estas obras avanzan linealmente, pero bajo esa superficie otros aspectos "saltan a la velocidad abismal y seductora de la catástrofe" $(s / n)$. Y agrega: "Lo maravilloso de algunas de estas obras geniales es que están armadas con partes iguales de orden y de caos, como el fractal de Mandelbrot" $(s / n)^{5}$. Se trata de una mímesis que, por un lado, pone a jugar los modelos complejos y no lineales del tiempo; $y$, por otro lado, que se presenta ostensiblemente como ficción, inclusive como "[m]entira que se presenta como tal" (s/n).

En El fin de Europa, dos de sus capítulos, "El fin de la historia" y "El fin de Europa", ponen a jugar estas ideas de un modo, a nuestro entender, bastante elocuente. Dos características refuerzan las operaciones de la ficción (teatral): por un lado, las dos piezas tematizan el mundo de la escena, se configuran fuertemente metateatrales -con sus actores, sus escenarios y sets de TV, sus vestuarios, sus ensayos y representaciones- haciendo del teatro y las formas más contemporáneas del espectáculo audiovisual los ejes de una reflexión también sobre el medio en cuestión. Por otro lado, se trata de los dos únicos capítulos cuyas relaciones entre título y tema no operan de forma lineal, como en el caso de los otros (la salud, la familia, la nobleza, el arte, las fronteras y la realidad), sino que presentan sentidos más ambiguos.

En el caso de "El fin de Europa", Europa es el continente pero también el título de una telenovela -o serie, en el texto se utilizan ambas denominacionesque se produce a la vez con un elenco norteamericano -con un presupuesto de lujo- y un elenco europeo -con un presupuesto magro-, bajo la lógica de una estricta división del trabajo cultural entre centro y periferia. Así, mientras la serie -caracterizada como un producto de ningún valor artístico- gira en torno a una

5 El interés de Spregelburd por la llamada ciencia de la totalidad lo lleva ya en 2001 a escribir y dirigir Fractal. Una especulación científica. Tanto en aquella oportunidad como aquí, el dramaturgo se vale la teoría del caos, la termodinámica, la teoría de la catástrofe y la geometría fractal de Benoît Mandelbrot, entre otros, para desarrollar sus ideas en consonancia con los paradigmas complejos de la realidad. Cf. Spregelburd ("Procedimientos"), Dubatti ("Hacia una relectura"), Abraham ("De la realidad") y Rodríguez Carranza. 
pareja romántica en el contexto de una intriga de espías con aires de guerra fría, la producción a dos elencos corre el riesgo de terminarse y los actores europeos de quedar sin trabajo. Sobre el final, ya lo decíamos, se despliega una temporalidad (y una voluntad) no humana, incognoscible, que solo se deja figurar en una acción en cámara lenta mediante la cual unos ángeles enviados por Dios asisten a los actores que se mueven a velocidad extraordinaria. Esa temporalidad que solo puede ser figurada bajo las coordenadas de la acción ralentizada de los ángeles es reforzada por una narración omnisciente y omnipresente, proyectada en una pantalla en la escena a la manera de intertítulos:

Asistimos a los últimos capítulos de "Europa".

[...]

Un grupo de asistentes trata en vano de mantener en pie el derrumbe de esta ficción tan querida por el público.

Pero no eran asistentes. Eran ángeles.

Lo cierto es que Dios había enviado a sus mejores agentes para proteger esta ficción llamada Europa ${ }^{6}$. (Spregelburd Segunda Parte 49)

El relato sin cuerpo ni voz refuerza la distancia entre lo narrativo y lo dramático / escénico poniendo el acento sobre el carácter ficcional de la propia escena teatral, pero también de lo misterio y sobrenatural en el plano de la ficción.

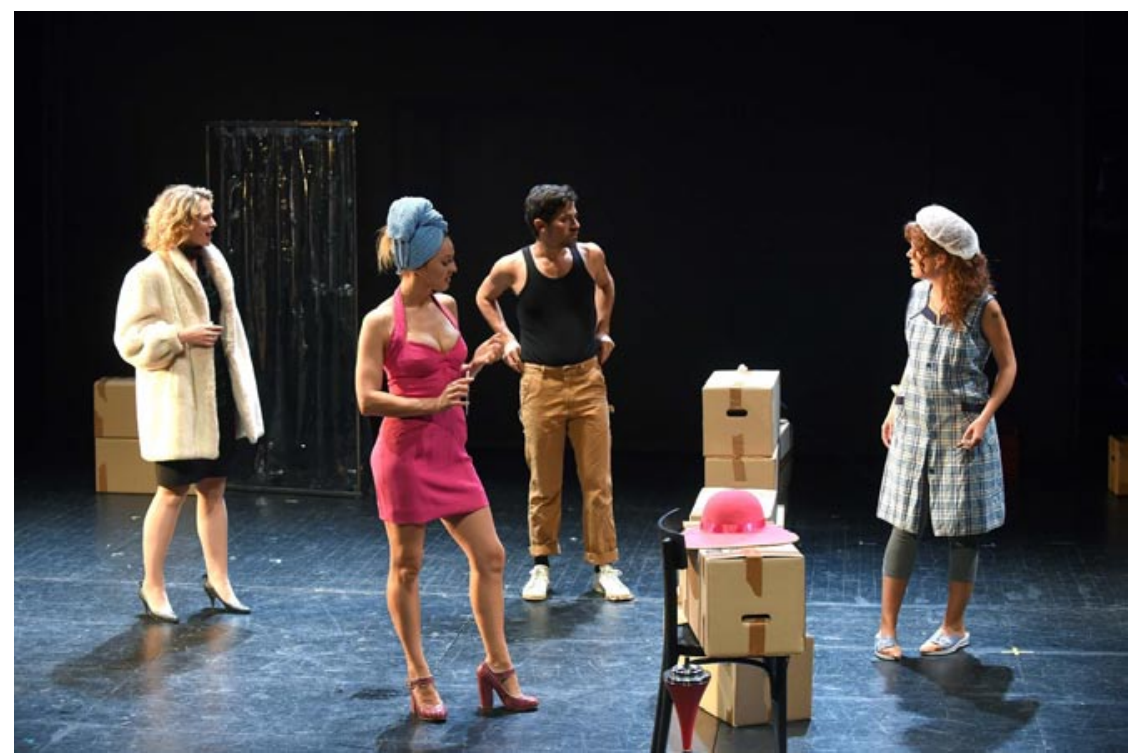

"El fin de Europa". Todas las imágenes pertenecen a la puesta en escena realizada en la Comédie de Caen, el Teatro Stabile di Genova y el Théâtre de Liège, 2017. Fotos: Gentileza de Rafael Spregelburd

6 Cada uno de estos fragmentos se repite en inglés, en italiano y en francés. 


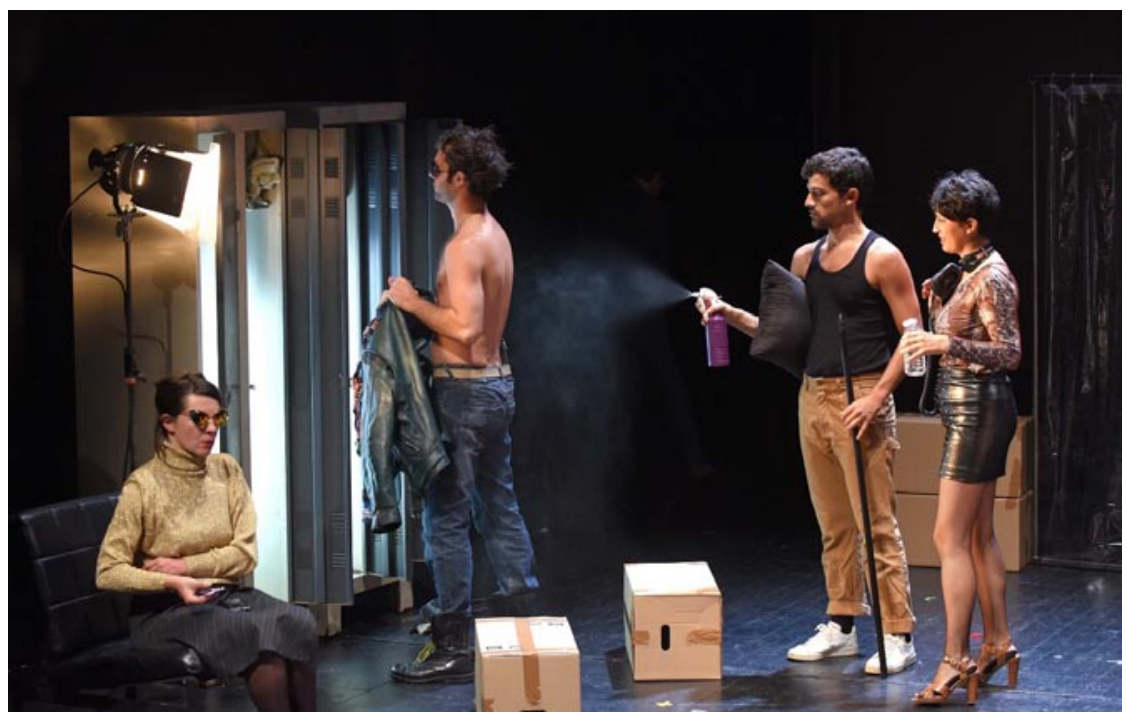

"El fin de Europa"

"El fin de la historia", por su parte, no aborda el fin de la Historia, sino la decadencia de una compañía teatral -por cierto, también de escaso valor artístico- y, más generalmente, del teatro como institución. Si en el caso de "El fin de Europa" sabemos recién al final que todo aquello que habíamos leído/visto ya había tenido lugar," en "El fin de la historia" se vuelve a repetir el procedimiento pero, en este caso, el futuro se irá desarrollando en paralelo al presente. Así, los actores teatrales pertrechados con vestuarios, escenografías, textos del repertorio y cierto oficio son, a la vez, presente y pasado. La relación entre acción escénica y narración a través del texto proyectado en la escena, sin embargo, no es del todo compatible: "A veces coinciden completamente con la escena, a veces solo parcialmente, a veces no coinciden en nada y sospechamos que las dos historias no son la misma" (Spregelburd Primera parte 29). A diferencia de "El fin de Europa" y los motivos insondables de Dios salvando al continente, aquí la historia se configura en una distancia más modesta entre el hecho menor de un cigarrillo apagado a tiempo y una placa conmemorativa que, años más tarde, homenajeará al heroico actor que salvó al edificio de un terrible incendio. De este modo, las relaciones entre causas y efectos y entre hechos y relato -si bien más lineales y explícitas que la carta que no le llega a Romeo- tienen algo de desmesura, de falta de correspondencia, y lo anodino puede volverse extraordinario a los ojos de la historia (y de su escritura).

7 Si bien la escena final de los ángeles sucede después de lo que hemos visto, como puede verse en la cita antes transcripta, los textos (tanto las didascalias como los que se proyectan en la pantalla en la escena) nos dan a entender, en el plano de la trama, que aquello que hemos visto ya sucedió. La escena final de los ángeles, entonces, resultaría un flashback que pone al descubierto el hacer de los ángeles y la trama secreta de Dios. 


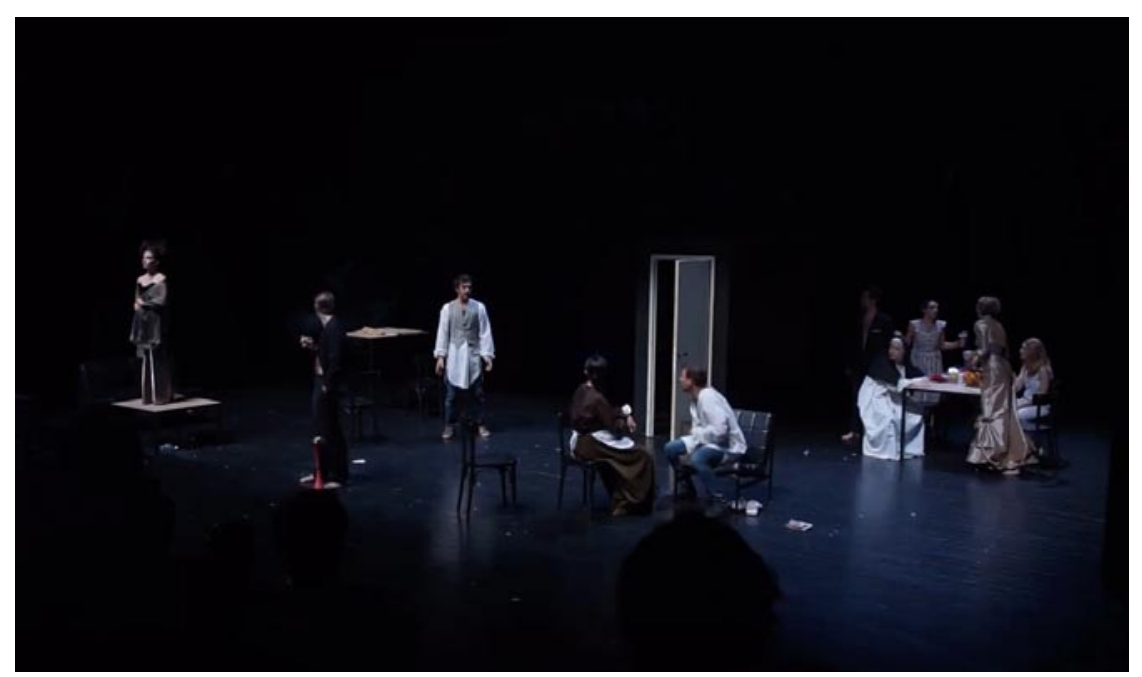

"El fin de la historia"

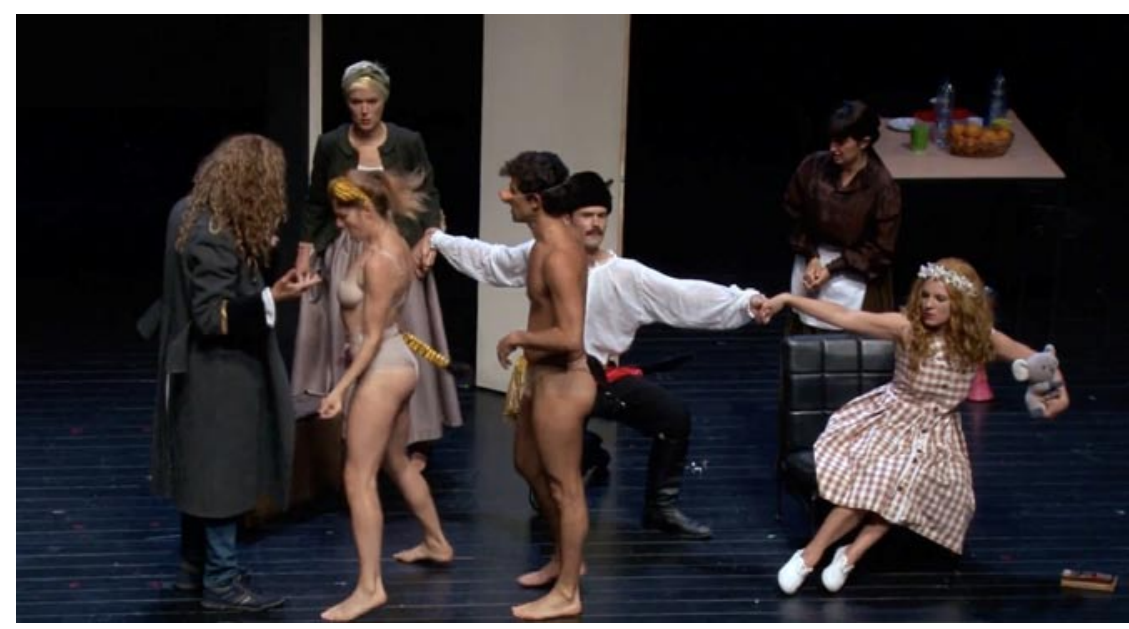

"El fin de la historia"

En su reciente trabajo sobre El fin de Europa Luz Rodríguez Carranza desarrolla una interesante lectura de la aproximación de Spregelburd a la temática del final: a través de la dialéctica en Hegel y Adorno, pasando por las elaboraciones de la teoría teatral sobre el tema, hasta las propias reflexiones del dramaturgo, la autora observa:

Consecuente con la segunda ley de la teoría de los conjuntos o del caos, Spregelburd propone -en sus obras, pero también en varios ensayos- una dialéctica que no conduce a ninguna síntesis ni final [...]. Sostiene, expresamente, una entropía positiva: una energía que se renueva y posterga el final fatalmente anunciado. (171) 
En esta postergación del final lo que se vuelve interesante es, según nos dice Rodríguez Carranza, lo que se hace antes del final, lo que sucede en el medio. $\mathrm{Y}$ aquello que sucede en el medio, entropía positiva mediante, responde a una lógica narrativa expansiva, llena de acciones sin sentido aparente, de personajes de escasos talentos en medio de situaciones que no logran manejar y, sobre todo, de conexiones causales más allá de nuestra compresión.

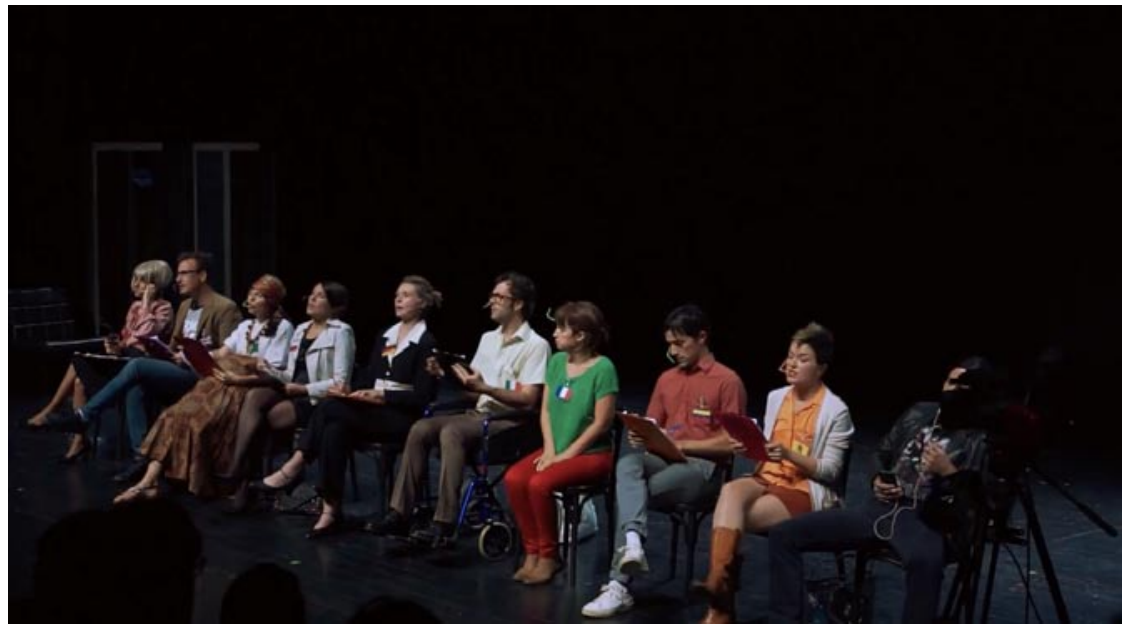

"El fin de la realidad"

\section{El malestar de lo contemporáneo}

Otra cuestión acecha de forma aún más perturbadora que el final: lo contemporáneo. De algún modo se asocia a la idea del final, pero no tanto en términos del fin de los tiempos, sino de cierta incapacidad de leer el presente, de ser alguien de su propio tiempo.

En "El fin de la historia" lo contemporáneo ingresa dos veces. Primero como una sensibilidad que la compañía teatral busca denodadamente alcanzar, más allá de las técnicas y repertorios conocidos, pero también más allá del fútbol, la pornografía y las redes sociales que han desterrado al teatro de su lugar como espectáculo. Luego, ingresa en el momento en que un trabajador del futuro descubre la placa conmemorativa del incendio y se preguntará por los artistas. En la pantalla que proyecta la voz narrativa en escena puede leerse: "Le cuesta imaginar que el sitio donde hace su trabajo estuvo alguna vez poblado de esos espíritus contemporáneos. [...] / Un frío inexplicable recorre su espalda. [...] / Y luego regresa a su trabajo". (Spregelburd Primera parte 38-39)

En ambos momentos lo contemporáneo ingresa en forma irónica, el desfasaje entre lo que la compañía despliega sobre el escenario y las referencias del teatro de vanguardia de las que echan mano está muy lejos de coincidir. La apelación a la sensibilidad y al espíritu dirige su mordacidad, creemos, a un doble y paradó- 
jico imaginario del arte: aquel del arte más avanzado y experimental y también de aquel otro del lenguaje y el mercado global. Se abre allí una distancia a la vez reflexiva y empática en la medida en que la labor vocacional de la compañía y la mirada abstraída del trabajador parecen devolvernos un sentido más profundo sobre lo contemporáneo, aquel de lo intempestivo, de la discontinuidad que permite percibir y aprehender aquello que resulta urgente y requiere atención en el presente, como nos recuerda Giorgio Agamben, articulando relaciones con el pasado.

La interpelación de lo contemporáneo encuentra, en el caso de "El fin del arte", grados de paroxismo hilarantes y a la vez catastróficos. Todo comienza con la conversación entre dos profesores universitarios (Valerie y Gastón) acerca de la incorporación del caso (real) de Cecilia Giménez, la anciana que en 2012 intentó restaurar una pintura de Cristo de la iglesia de su ciudad, Borja, y termina por transformarlo en un mamarracho de difusión viral ${ }^{8}$. La noticia del Ecce desafía, según Valerie, el canon del arte contemporáneo y las declaraciones de la anciana (mezcla de culpa y devoción), se instalan en el meollo de los misterios de la creación. Gastón, por su parte, descreído y ácido, no encuentra forma de justificar esas ideas y en cambio se defiende de lo que cree en verdad son las solapadas acusaciones en su contra de un estudiante, Julien. Del hombre de Neanderthal pintando las cuevas de Chauvet hasta Damien Hirst, los profesores debaten acerca del arte, el lenguaje, las fronteras, la "dialéctica de lo inaprensible" (Spregelburd Primera parte 12). Hasta que llega la estudiante París con su padre, solicitando que se le explique por qué Valerie desaprobó su tesis, cuyo título es: "El fin del arte: la revolución inconsciente de Cecilia Giménez de Borja en Zaragoza o pintando con mostaza arriba del puré". Los profesores se unen para justificar la decisión (al menos Gastón no hace nada en contra) y París termina yendo literalmente a "lavar los platos" en el restaurante de su padre portugués.

Gastón: No digas nada.

Valerie: Bueno.

Gastón: Le arruinaste la vida a una persona. Mejor no digas nada.

Valerie: Bueno. Ahora no voy a decir nada.

Gastón: A una persona contemporánea. Le arruinaste la vida.

Valerie: Tenés razón. Hice un estrago. Mi duda condujo a un estrago. Y nadie me detuvo. Esta chica tal vez no derroche luces a su paso. Pero esta chica es contemporánea. Es más contemporánea que vos y que yo. Cuando vos y yo ya no seamos capaces de entender las imágenes, ella aún sabrá mirar. [...]

Gastón: No digas nada más.

Valerie: No. Es lo que corresponde. Pero después, más tarde, la semana que viene, a más tardar el lunes 20, habrá que encontrar una solución. Y yo no la tengo.

Gastón: No, yo tampoco. (Spregelburd Primera parte 18)

8 La noticia resultó en su momento muy conocida y el propio Spregelburd la comenta a propósito de los acontecimientos y noticias que circulaban al momento de realizar la residencia en la École de Maîtres según citábamos anteriormente. 


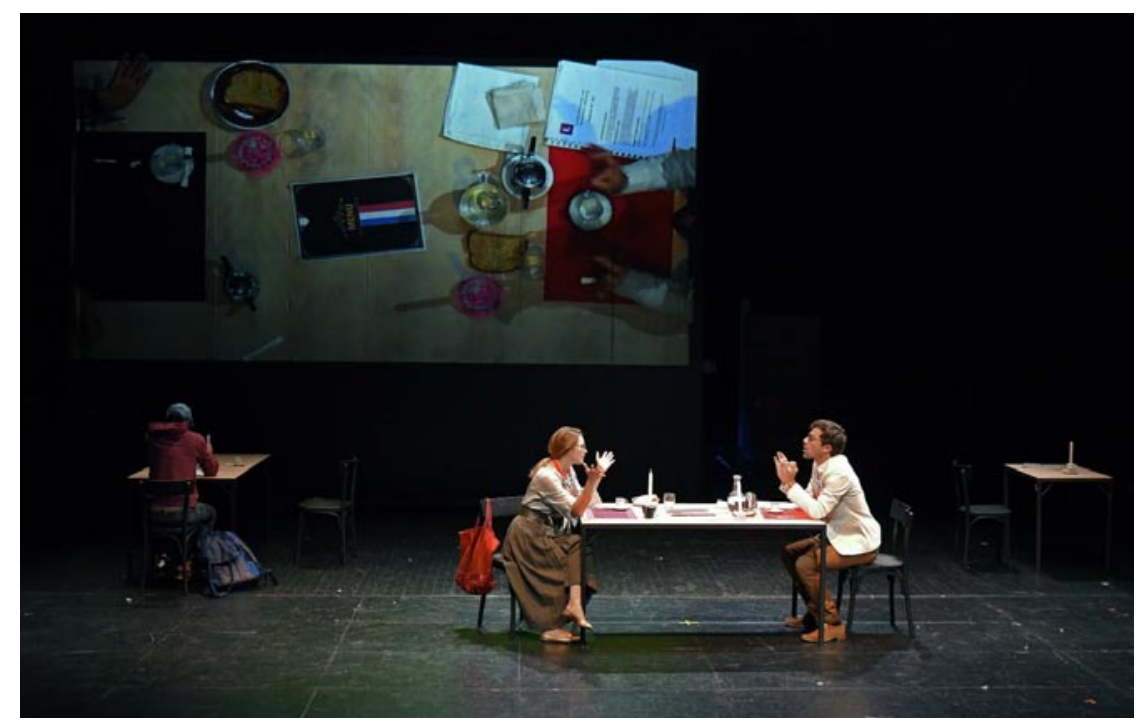

"El fin del arte"

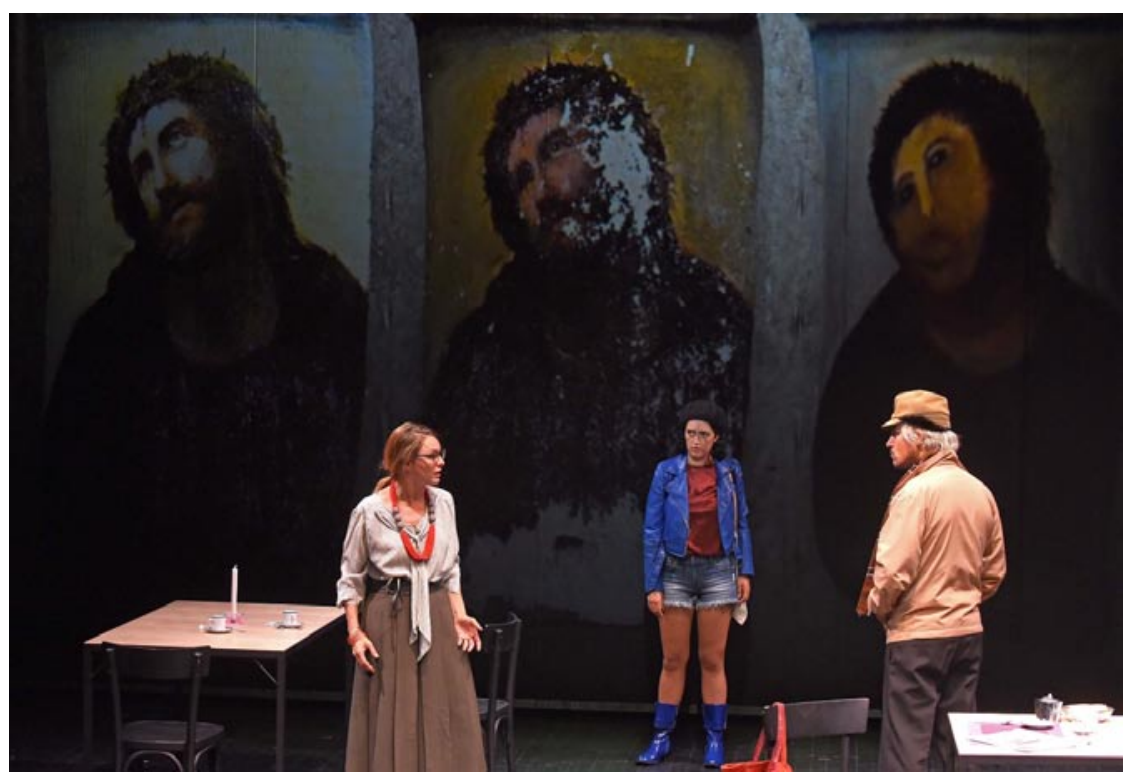

"El fin del arte"

Poder/saber mirar, todo parece jugarse allí, en los regímenes de visibilidad que se habilitan en las instituciones y más allá de sus márgenes. Saber/poder mirar en la clave trastornada de la que habla Mieke Bal es justamente la empre-

9 Su traductora, Remedios Perni Llorente, explica respecto de la traducción del término preposterous: "En español disponemos de una palabra parecida pero ligeramente diferente: prepóstera 
sa que propone emprender para delinear un pensamiento crítico en torno a la visualidad como operación de lectura del presente en diálogo con el pasado (en clara relación, como puede verse, con la conceptualización de lo contemporáneo a la que hacíamos referencia anteriormente).

El fin de Europa en su conjunto y las piezas que acabamos de recorrer apuntan justamente a ese gesto contemporáneo a través de personajes que intuyen ese umbral, que los interpela y que al mismo tiempo los instiga a hacerse preguntas, los pone en jaque en relación a su capacidad de poder ver, poder leer, poder estar a la altura de las circunstancias que el (su) tiempo histórico (y personal) requiere. Así, desconcertados, algunos perciben que algo no funciona, aunque no pueden vislumbrar la cuestión en su complejidad; otros ensayan acciones catastróficas con una vocación, una libertad, una ingenuidad y una torpeza que termina por descolocar a aquellos que buscan explicarlos, ponerlos en un lugar; otros personajes, finalmente, frente a lo anómalo, la duda o la perplejidad, arremeten con toda la fuerza del statu quo. Entre unos y otros, las piezas ponen en juego dislocaciones de la lógica causal de la historia (paralelismos, retrocesos, en los casos de "El fin de la historia” y "El fin de Europa”), y también múltiples temporalidades en conexiones más o menos inesperadas con el presente (y así, Cecilia Giménez resulta la encrucijada donde se cruzan los dibujos de las cuevas de Chauvet, los iconoclastas y el arte contemporáneo, pero también lo sagrado y la fetichización de la imagen, la historia del arte y el giro cultural del capitalismo contemporáneo, la experticia disciplinar y el bricolaje amateur, el rostro de Cristo y el meme viral) ${ }^{10}$.

Valerie: yo entro en el aula, aferrada así a esta carpeta, y tengo una sensación, como un frío en la espalda, una sensación sin nombre, que ahora empieza a llamarse Cecilia Giménez (Spregelburd Primera parte 8)

Nuevamente, como en el caso de la escena el trabajador del teatro, aquí también lo intempestivo ingresa como un frío en el cuerpo, una sensación más allá de lo nombrable que exige una mirada, un pensamiento. Y son justamente las figuras anónimas, la gente común, los “cualquiera” -la anciana de Borja, la estudiante París, la compañía teatral, el trabajador que se detiene a mirar la placa conmemorativa-, como observa Rodríguez Carranza, aquellos que detienen la

[sin embargo] hemos optado por traducirla como trastornada, pues abarca tanto la idea de invertir el orden regular de algo como la de tener el sentido perturbado" (en Bal "Nota del traductor" 17-18).

10 Este tratamiento de la temporalidad trastornada se ve acompañado, según Bal, de operatorias barrocas sobre la imagen, entre ellas, los juegos y efectos anamórficos (a la vez superficie deformada y reversible que deja ver, o al menos intuir, sospechar, otra perspectiva de la realidad). Lo catastrófico y a la vez hilarante de la restauración de la imagen de Cristo es justamente la literalidad de la deformación. Provoca perturbación y, a la vez, alumbra otra forma de mirar (y pensar) la imagen de lo divino, pero sobre todo su relación con la realidad. 
entropía, renuevan la energía, abren un lugar que no estaba y lo transforman en un acontecimiento.

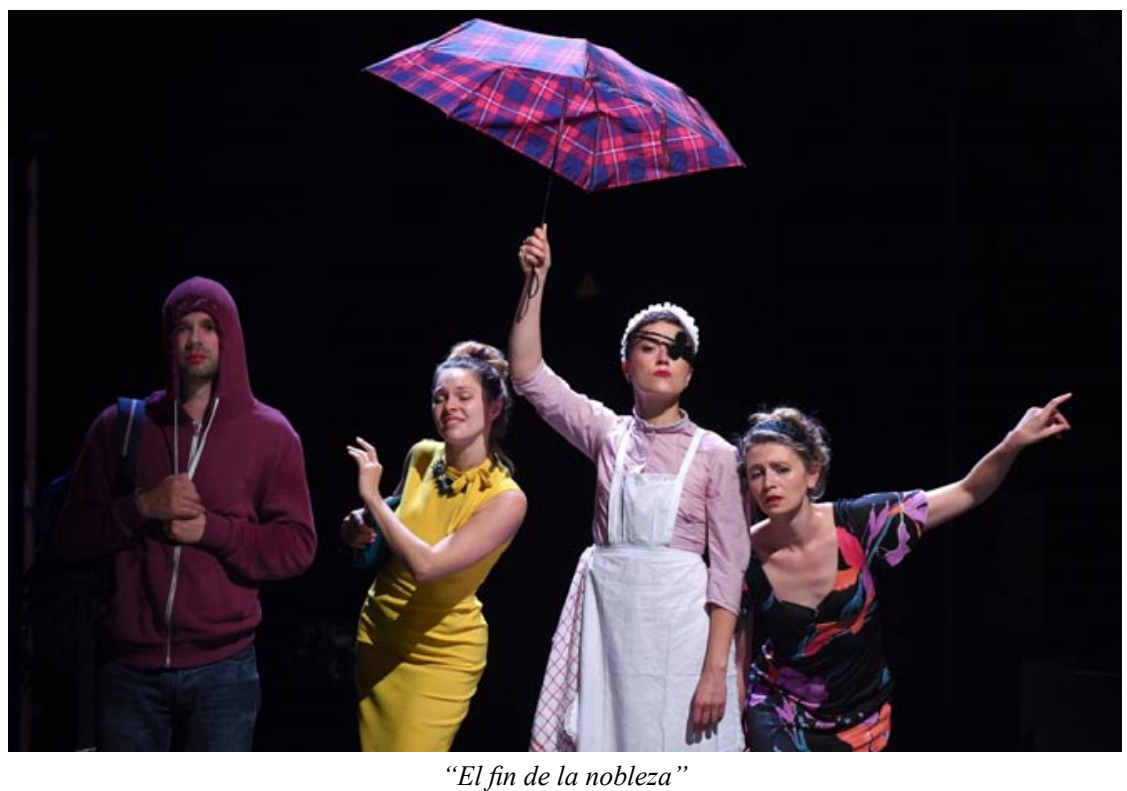

\section{Una dramaturgia de fascículos perdidos}

Decíamos al iniciar este trabajo que El fin de Europa puede caracterizarse como un proyecto serial que resulta, a nuestro entender, de particular interés no sólo en relación a anteriores producciones del dramaturgo, sino también en concordancia con algunos formatos renovadores de la escena teatral argentina contemporánea.

En relación a la noción de serie retomo las reflexiones de Beatriz Trastoy. En sus propias palabras:

Una serie es una sucesión de unidades relacionadas entre sí por algún rasgo intrínseco a la luz de la lógica que las conecta. Este rasgo común y el criterio de ordenación que relaciona las unidades de cada serie son tan importantes como el intersticio de tiempo o de espacio que las separa y, a la vez, las vincula, convirtiéndolas precisamente en lo que son, es decir, en unidades distintas, especiales, diferentes entre sí. (212)

Partiendo de esta breve definición la autora reúne un importante corpus de trilogías, tetralogías y decálogos teatrales, entre otros formatos, y distingue dos tipos de proyectos serializados: aquellos realizados por un mismo artista y aquellos otros que responden a una convocatoria curatorial a diferentes artistas con el propósito de realizar un ciclo. En ambos casos, la conexión puede estar dada por 
rasgos temáticos y/o procedimentales comunes, así como por la diferencia que articula igualmente la relación entre las piezas. Otro rasgo sobresaliente, según la autora, es el alto grado de explicitación de su propio programa productivo o principio generador, una forma autorreflexiva, a la vez teórica y práctica, del propio quehacer teatral que incluye los múltiples sentidos que se habilitan individualmente y como conjunto y, finalmente, en relación a la recepción generada y modelizada por la propia serie.

Entre las producciones anteriores de Spregelburd dos proyectos han desarrollado distintos formatos que bien pueden servir de ejemplo para pensar algunas experiencias en torno a esta matriz productiva. Se trata de la Heptalogía de Hieronymus Bosch (1996-2008) y Bizarra. Una saga argentina (2003).

En el caso del primer proyecto, como su título lo indica, se trata de siete obras que tematizan la Mesa de los Pecados Capitales de El Bosco ${ }^{11}$. Al igual que El fin de Europa, son obras independientes, escritas en un extenso período de tiempo, conectadas por el tema o premisa que las congrega. La conexión en la Heptalogía, explica Spregelburd, no es argumental sino lúdica y establece una modalidad de lectura particular: "El juego consiste precisamente en descubrir cuál es el juego. Los espectadores atentos pueden detectar que lo que es irrelevante en una de las piezas, es retomado como relevante en otra de ellas. Y el orden en el que uno las leyera determinaría el paseo por ese laberinto hipernarrativo" (en Locatelli s/n).

El segundo proyecto, Bizarra, producida y estrenada en el contexto de la crisis argentina del 2001, consistió en una teatronovela de diez capítulos ${ }^{12}$ en la que dos hermanas, separadas al nacer, atravesaban todas las peripecias sentimentales, de identidad y de clase propias de las heroínas del género, en el contexto de la profunda crisis que atravesaba tanto a la fábula como al proyecto y a su recepción. A diferencia de la Heptalogía y de El fin de Europa, aquí los capítulos resultan interdependientes, su orden y progresión argumental es fundamental para sostener la serie y hacerla legible. Al igual que El fin de Europa, el clima de crisis que las emnarca así como su tematización las conecta a pesar de las distancias geográficas y temporales que las separan. Como observa Rodríguez Carranza: "Bizarra expuso la desaparición de todos los lugares simbólicos e identitarios argentinos con la crisis del 2001-2002, pero en 2012 la intemperie no tenía ya fronteras" (172).

Nos interesa señalar aquí el modo en que en todos los casos se activa un pensamiento y una práctica teatral más allá de la obra individual y autónoma, con un relato único, autosuficiente y cerrado en pos un trabajo creativo que

11 Las piezas son: La inapetencia, La extravagancia, La modestia, La estupidez, El pánico, La paranoia y La terquedad. Su producción se extiende de 1996 a 2007. La última de las piezas tuvo un estreno en Alemania en 2008 y pudo verse en Buenos Aires recién en 2017. Sobre el proyecto, cf. Locatelli.

12 Las entregas se hicieron primero semanalmente a lo largo de diez semanas y luego en un formato "reciclado" de todos los capítulos durante dos semanas. Sobre la experiencia, Cf. en Spregelburd (Bizarra) el epílogo/conversación junto a Javier Daulte y Locatelli. 
desarrolla no sólo un pensamiento complejo sobre la construcción de la ficción sino también de sus formatos y extensiones más tradicionales ${ }^{13}$.

En el caso de El fin de Europa, como decíamos, se compone de ocho historias breves, independientes entre sí y a su vez con un conjunto identificable de motivos que se van repitiendo a lo largo de cada pieza: el lenguaje y la frontera como conceptualizaciones que intentan fallidamente aprehender algo del orden de la realidad ("El fin de las fronteras", "El fin de la realidad", "El fin del arte"); un desfile de personajes mezquinos, narcisistas y necios atrincherados en un status quo que están dispuestos a defender a pesar de la evidencia de su derrumbe (su tratamiento satírico puede verse en todas las piezas de la obra); y una imagen religiosa transformada en meme que viaja de un episodio a otro para transformarse, a través del hueco de sus ojos, en un artefacto capaz de ver la realidad de los ángeles ("El fin del arte", "El fin de Europa").

Y así como están los motivos que se repiten también se encuentran, como decíamos anteriormente, los múltiples detalles inconexos, sin sentido, hasta gratuitos y de asociaciones indirectas e inverosímiles que por su misma proliferación, sin embargo, también terminan generando sistema más allá de que sus sentidos resulten más misteriosos: ¿Por qué Valerie se introduce una vela en la vagina aprovechando un alto en su discusión sobre Cecilia Giménez, mientras Gastón va al baño? ¿Por qué el incidente del cigarrillo que no llega a ser incendio se transforma en una placa recordatoria con el correr del tiempo? Y finalmente, ¿por qué Dios a veces ayuda y otras abandona al hombre y su civilización? Imágenes, gestos, acciones, personajes y sobre todo palabras se acumulan sin jerarquía $a^{14}$ y señalan, a pesar de su opacidad, que algo está sucediendo allí (o tal vez en otro lugar) y que a pesar de que no podamos comprenderlo, como señala Sandra Contreras, nos dejan pensando.

El fin de Europa con sus piezas pone finalmente en juego una serie de "casos" que individual, parcial o conjuntamente pone a prueba ciertas ideas en tanto ensayos críticos a la vez que piezas artísticas. Sobre ello el propio Spregelburd

13 En el trabajo de Spregelburd la reflexión sobre la unidad de la obra de arte está presente tanto en términos teóricos como prácticos. En relación a Todo (2009), por ejemplo, decía lo siguiente: "[...] la multiplicidad de lo único (esta obra son tres obras, o sólo una que dice tres fábulas diferentes y sin moralejas) es motivo para mí de goce y de conflicto". (Spregelburd Todo 14-15).

14 Entre sus referentes, Spregelburd encuentra en Eduardo Del Estal y sus reflexiones sobre la relación entre figura y fondo una conceptualización que le permite vincular el acto perceptivo, el pensamiento y el lenguaje. En este ámbito, a la forma le corresponden los conceptos de significado, necesidad y orden, mientras que al fondo las nociones de sentido, azar y caos. Forma y fondo, significado y sentido, se organizan, de este modo, en lo que Del Estal llama la "maquinaria de la significación" que opera mediante una dialéctica sin síntesis porque cada vez que la mirada pasa de la figura al fondo, este pasa a ocupar el lugar de una nueva forma que reclama, a su vez, de un nuevo fondo. La relación entre significado y sentido se articula entonces en una dialéctica sin instancia superadora. Cf. Spregelburd ("Procedimientos") y Abraham ("De la realidad"). Véase que aquí reaparece, bajo la conceptualización de la "maquinaria de la significación", las reflexiones de Rodríguez Carranza acerca de la dialéctica sin síntesis que opera en la matriz poética de Spregelburd. 
señalaba a propósito de Tres finales, una de las puestas en escena de la saga: "Tres bocetos a mitad de camino entre lenguajes escénicos (teatro, performance, danza, concierto barroco, y por qué no, mamarracho, ensayo teórico, work-in-progress ya fijo y estancado) como un fascículo perdido de alguna enciclopedia sobre lo Contemporáneo: El fin del arte, El fin de la realidad y El fin de la historia"15.

Así, esta dramaturgia de fascículos perdidos opera por fragmentos que, no obstante, en sus mutuos puntos de contacto, reenvíos y diferencias permiten aproximarse a la premisa del final. El encuentro con los fascículos, como un objeto fractal (escala mediante), nos permitirá imaginar lo que no está, lo que falta, lo que se ha perdido. Y esta dramaturgia representa una metodología que la emparenta con aquella historia trastornada que propone Bal, en contacto con las figuras del archivista, el arqueólogo -e inclusive del basurero- ${ }^{16}$ y la conceptualización contemporánea de la historia y el tiempo.

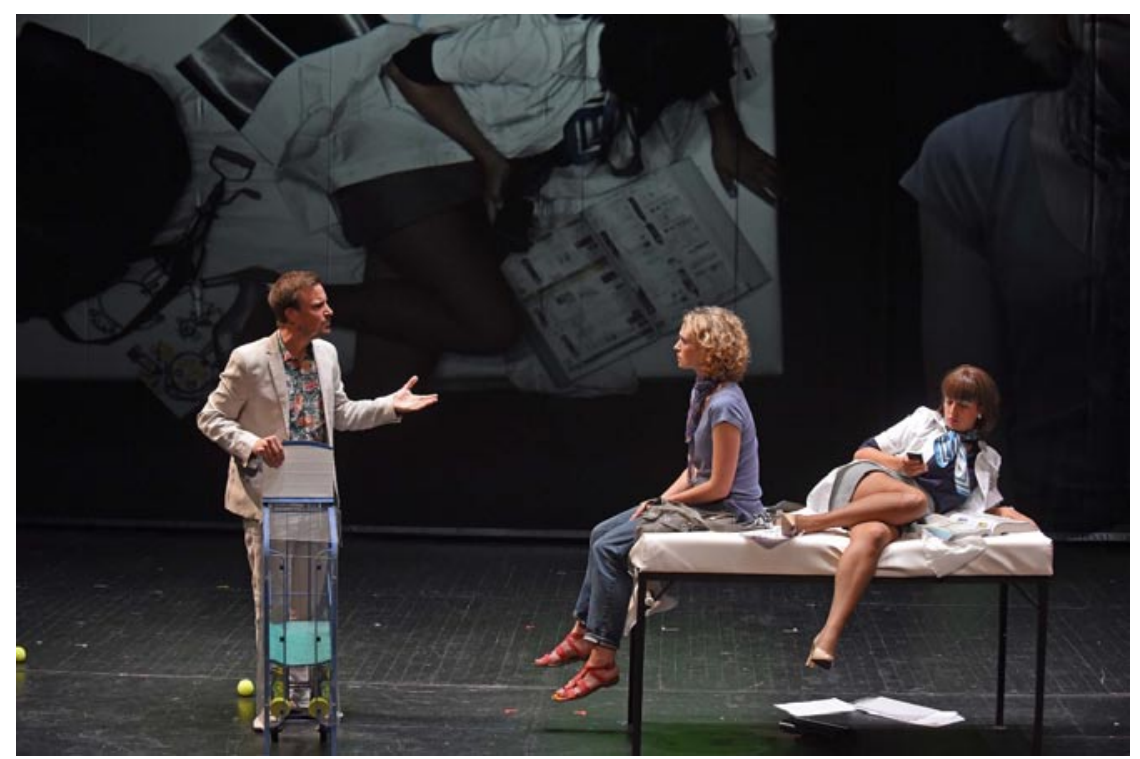

"El fin de la salud"

$15 \mathrm{http}: / / \mathrm{www} \cdot$ alternativateatral.com/obra41628-tres-finales

16 "Como dramaturgo soy bastante parecido a un recolector de basura, voy juntando material sin saber muy bien para qué" (en Giraldo $s / n$ ). 


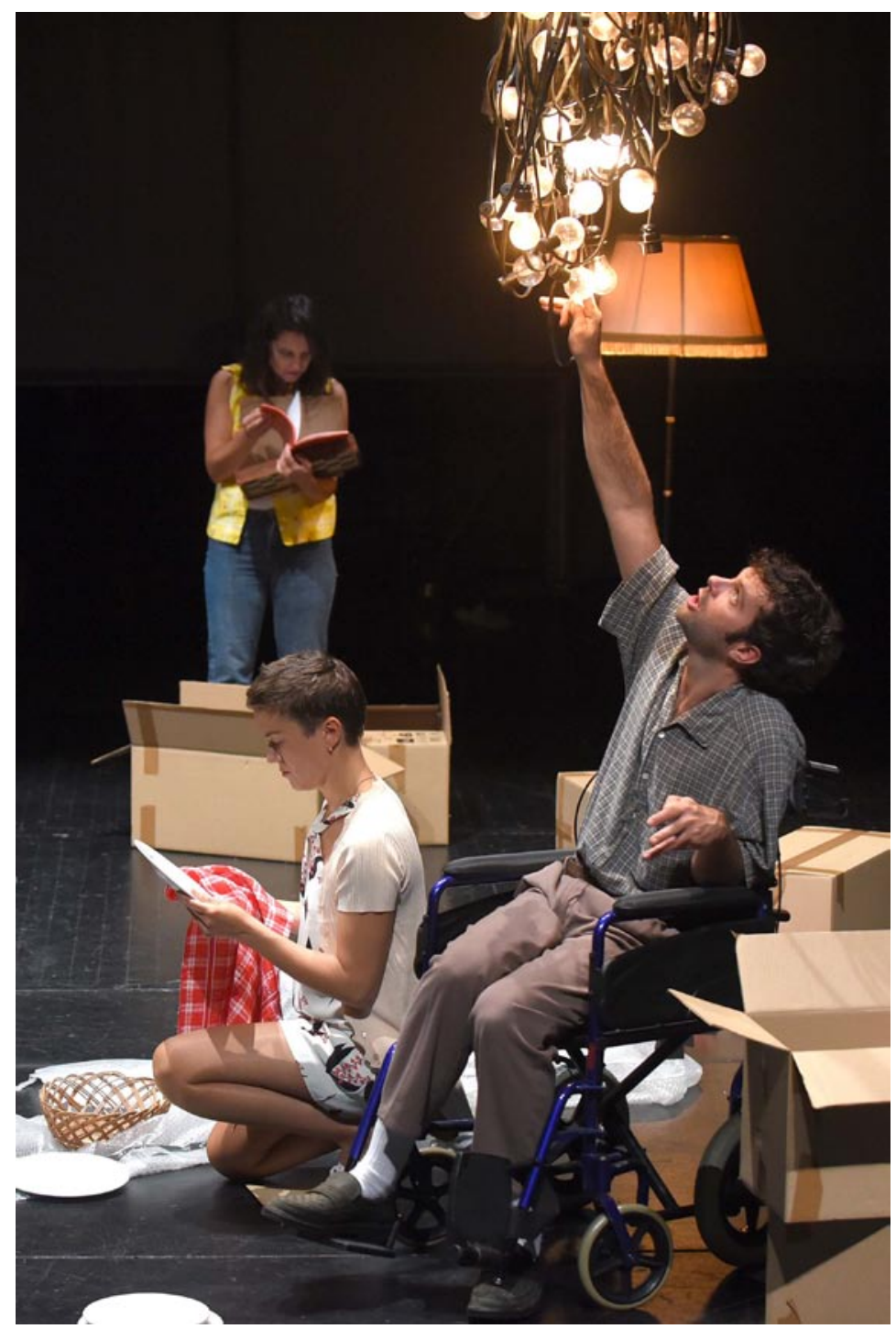

“El fin de la familia”.

\section{El fin del relato (teatral)}

Quisiera concluir con una reflexión acerca de otro sentido del fin: aquel de la finalidad. Podríamos preguntarnos cuál es el propósito de las instituciones y conceptualizaciones a lo largo de las piezas que conforman El fin de Europa (el arte, la historia, la realidad, Europa, las fronteras, la nobleza, la familia, la salud). La respuesta resulta bastante contundente y la expresa Valerie, la profesora de "El fin del arte": 
Valerie: ...y que la imagen divina -ya devaluada por su propia repetición en serie- se puede retorcer como un pulóver viejo y acabar empíricamente con el problema de los iconoclastas, desde Bizancio hasta Warhol. Y si esto es así, si entonces cualquiera puede canalizar su furia y retorcer las imágenes de las cosas porque sí, transformar lo que no tiene gran valor artístico y convertirlo en otra cosa, en otra que dice "acá estoy"... Si "acá estar" es el único valor que se le puede reconocer a la obra de arte, entonces la carrera que su hija pretende hacer, que se llama "Arte", ya no existe más, ya no se llama nada. (Spregelburd Primera parte 16)

Aquí el fin como propósito, como finalidad se homologa al fin como clausura, como cierre de un paradigma (y su tiempo). Como decíamos anteriormente, lo que todas y cada una de las piezas de El fin de Europa intentan pensar es justamente ese umbral en donde un modelo (de sentido y orden) está resquebrajándose. Su vigencia está desmoronándose, su tiempo se está acabando (o al menos es lo que se percibe en el horizonte) y eso es lo que varios de los personajes interpretan como una calamidad. Resta entonces pensar acerca de la naturaleza de aquello que está por venir. De identificar si aquello que se está gestando para ese tiempo posterior no es otra cosa que un reordenamiento del poder instituido (como señala el propio Spregelburd), o bien la posibilidad de otro orden. La historia siempre se cuenta con posterioridad; la coyuntura (y la ficción) resulta, en cambio, más incierta.

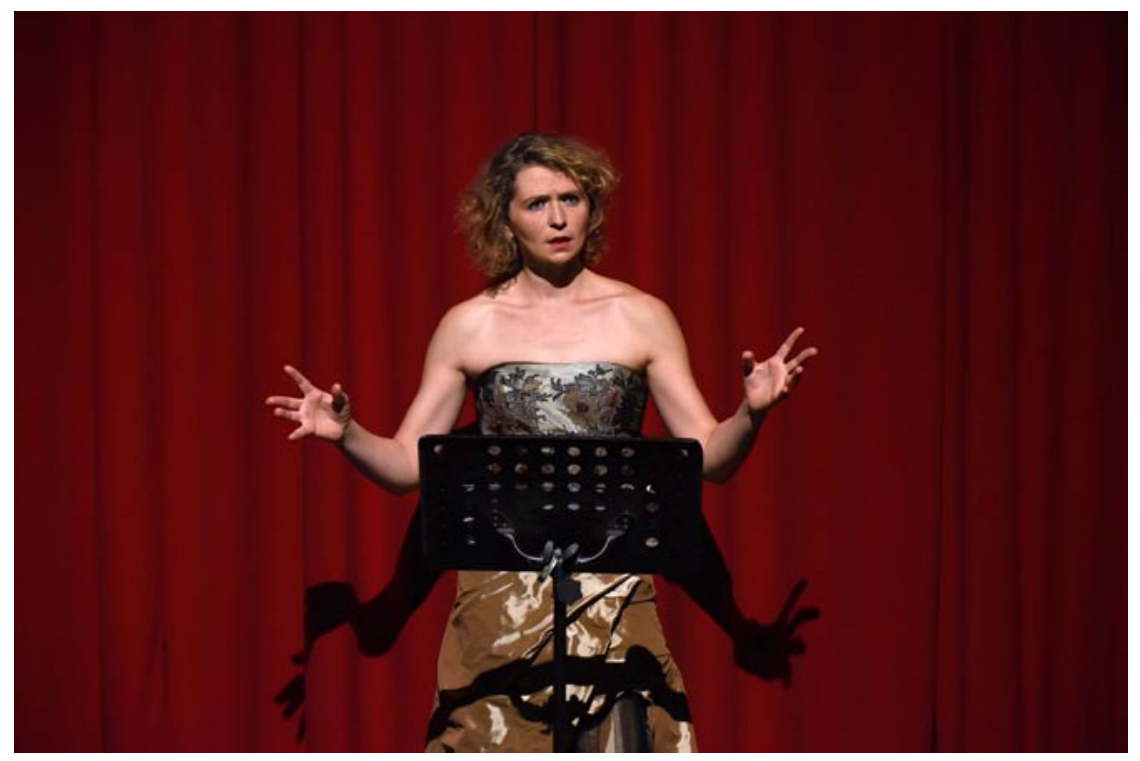

"El fin de las fronteras"

Me interesa hacer una pregunta derivada de la anterior: ¿cuál es el fin (en tanto finalidad) del trabajo del arte sobre estos problemas? Más precisamente, ¿cuál es el fin del trabajo teatral según Spregelburd? Para responder podríamos 
considerar dos aspectos del trabajo (artístico, teatral) que se ponen en juego: el de su propio hacer y el de su contacto con su tiempo.

Decíamos inicialmente que la obra fue gestada en el marco del laboratorio de la Ecole de Maîtres, donde Spregelburd trabajó con un grupo de actores de distintos países y con materiales diversos (tanto ficcionales como reales). El proceso se extiende en el tiempo y se lleva a cabo a través de varias reescrituras, ensayos y puestas en escena. Al final de la saga puede leerse: "Escrita y ensayada entre septiembre de 2012 y octubre de 2017 en las ciudades de Udine, Coimbra, Roma, Liège, Buenos Aires y Caen" (Spregelburd Segunda Parte 53). No resulta singular que el proceso de escritura de un texto teatral -o de cualquier otro género- lleve cinco ańos o más. Lo que resulta propio del teatro es, creo, su posibilidad de ensayarlo, ponerlo a prueba, más allá de la palabra y la mirada única del autor, mediante la puesta en voz y en acto de los actores y la escena. ${ }^{17}$ El germen en el contexto del laboratorio habilita ese proceso no solo en relación con los actores, sino a través de las múltiples geografías e idiomas en los que el texto irá tomando forma. Ese registro final de un espacio-tiempo colectivo, extendido y diverso vuelve visible, para el lector, un cronotopos propio, ya no de la ficción, sino del hacer (teatral) en tanto proceso y proyecto.

$\mathrm{Al}$ referirse a La estupidez (2003), una de las obras que componen La heptalogía, Contreras observa que el interés del dramaturgo por la extensión no es como "la actitud vanguardista que hace de la duración extrema un estandarte con el que ofender el sentido común estético, desquiciar la percepción, destruir los módulos temporales cotidianos [sino que se identifica, en cambio, con el] entusiasmo ante lo gigantesco, lo desaforado, lo descomunal, lo inusitado (el vocabulario cambia), como exploración y celebración de las potencias" (363). Así, según la autora, no solo cambia el vocabulario, sino también la sensibilidad. Y esa sensibilidad está ligada no solo al interés de Spregelburd por "multiplicar exponencialmente las capacidades narrativas del relato" (363), y "sobreimprimir sobre el mundo la realidad compleja de la fábula" (364), sino también a un modo de concebir la actividad artísticas a contrapelo "de la transacción a corto plazo" de las formas de producción cultural contemporánea (362). En esa dirección apunta también, creemos, El fin de Europa.

Y en este camino lo encuentra la pandemia en 2020, cuando se disponía a escribir un nuevo capítulo de Bizarra, con motivo del vigésimo aniversario de su estreno. Así, un nuevo episodio se abre para la escritura de aquella teatronovela y un segundo tiempo extiende la larga duración de aquel proyecto cuando acontece lo inesperado:

17 Esta dinámica de trabajo con los actores y la escena en articulación con la escritura del texto resulta clave en la poética de Spregelburd y puede rastrearse a lo largo de su producción, particularmente en su labor con la compañía El Patrón Vázquez, junto a Andrea Garrote y otros artistas. cf.: Abraham ("Entrevista"), en Spregelburd (Bizarra) el Epílogo/conversación junto a Javier Daulte y en Spregelburd (Todo) el Prólogo/entrevista con Jorge Dubatti. 
Por circunstancias que no vienen al caso, hace unos meses que vengo rumiando la idea de escribir "El Once", el tan esperado como demorado capítulo 11 de esta saga. Se trataría de los mismos personajes (la mitad del elenco moría en acción, pero no cuesta un pomo revivirlo) diecisiete ańos después. Estamos los que fuimos y ganas no faltan, hemos envejecido y hemos mutado; la obra sería la obra y esa mutación. El plan era usar la estructura demencial de ese texto para reseńar y apuntar la debacle de la era neoliberal en la Argentina. En esto estábamos cuando pasó lo que pasó en Wuhan, Teherán, Milán, Madrid. ¿Qué hacer ahora? [...] Nada sé. Seguramente se tratará de escribir igual, sin saber nada, sin esperar nada, como si no hubiera ningún futuro o como si hubieran todos los futuros posibles. Y eso, una vez más, también ha sido siempre así. Quizás no nos dábamos cuenta. (Spregelburd "El año del cochino"116-117)

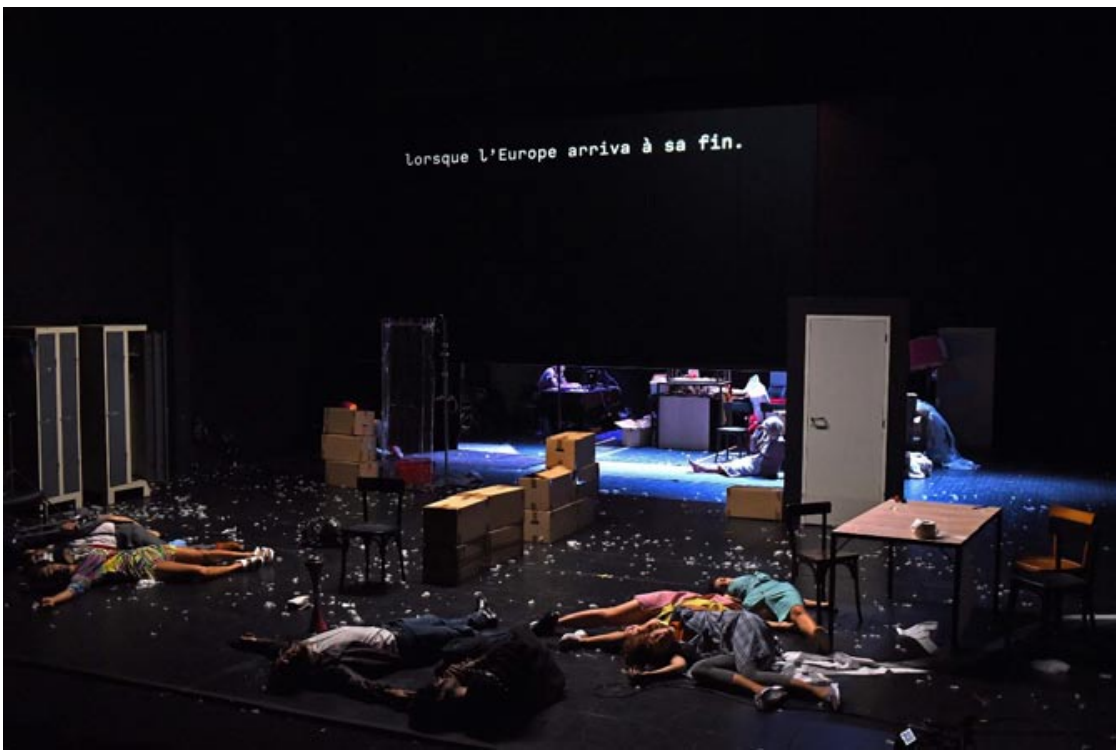

"El fin de Europa"

\section{Referencias bibliográficas}

Abraham, Luis Emilio. "De la realidad como 'mero' lenguaje a un lenguaje para la 'mera' realidad: el teatro de Rafael Spregelburd”. Revista Teatro XXI, XIII, no 25, 2007. http://archivoartea.uclm.es/textos/de-la-realidad-como-merolenguaje-a-un-lenguaje-para-la-mera-realidad-el-teatro-de-rafael-spregelburd/

. "Entrevista a Rafael Spregelburd". Boletín GEC, no 17, "Discusiones sobre teatro argentino actual". https://revistas.uncu.edu.ar/ojs/index.php/ boletingec/article/view/1144

Agamben, Giorgio. “¿Qué es lo contemporáneo?”. Desnudez. Buenos Aires, Adriana Hidalgo, 2011. 
Bal, Mieke. Tiempos trastornados. Análisis, historia y politicas de la mirada. Madrid, Akal, 2011.

Contreras, Sandra. "Formas de la extensión, estados del relato, en la ficción argentina contemporánea (a propósito de Rafael Spregelburd y Mariano Llinás)". Cuadernos de Literatura, Vol. XVII, no 33, ene-jun, 2013.https://www. redalyc.org/articulo.oa?id $=439843030017$

Dubatti, Jorge. "Hacia una relectura post-postmoderna del teatro argentino: notas sobre Rafael Spregelburd”.Revista Nuestra América, no 2, ago-dic, 2006. https://bdigital.ufp.pt/bitstream/10284/2370/3/171-181.pdf

. "Rafael Spregelburd: el grado cero de la utopía". Cien años de teatro argentino. Buenos Aires: Biblos/Fundación OSDE, 2012.

Giraldo, Pablo. "Rafael Spregelburd 'La idea del fin de Europa le viene bien al poder establecido'" Entrevista en El español, 21 ene. 2017. https://www. elespanol.com/cultura/escena/20170120/187482176_0.html

Halfon, Mercedes. "La obra incompleta". Radar-Página 12, 19 jun. 2016. https://www.pagina12.com.ar/diario/suplementos/radar/9-11583-2016-0623.html

Locatelli, Marina. "Entrevista a Rafael Spregelburd. Precisión y asimetría”. Revista Arte Críticas, oct. 2016. http://repositorio.una.edu.ar/handle/56777/865

Rodríguez Carranza, Luz. "Rayos en la oscuridad". HeLix, vol. 14, n o 2, dic. 2020, "Sujetos sin topologías: imposibilidad referencial y potencias combinatorias en la literatura y las artes latinoamericanas".https://journals.ub.uniheidelberg.de/index.php/helix/article/view/77794

Spregelburd, Rafael. "Procedimientos". Fractal. Una especulación cientifica, Buenos Aires, Universidad de Buenos Aires, Libros del Rojas, 2001.

. "Guía rápida para dramaturgos cazadores de catástrofes". Revista (Pausa.) Quadern de teatre contemporani, $\mathrm{n}^{\circ}$ 24, 2006.https://www.revistapausa.cat/ guia-rapida-para-dramaturgos-cazadores-de-catastrofes/

. Bizarra. Una saga argentina. Buenos Aires, Entropía, 2008. 2011.

Todo. Apátrida doscientos años y unos meses. Envidia. Buenos Aires, Atuel,

"El fin de Europa”. Perfil, 2 nov. 2012. http://www.cssudine.it/media/ progetti_annate/44_7159_rassegna_stampa.pdf

. El fin de Europa. Primera y Segunda Parte. Material inédito compartido por el autor, 2017.

. "El año del cochino". La fiebre, Maristella Svampa et. al., ASPO, 2020. https://www.upc.edu.ar/wp-content/uploads/2015/09/La-Fiebre-ASPO.pdf

Trastoy, Beatriz. La escena posdramática. Ensayos sobre la autorreferencialidad. Buenos Aires, Libretto, 2018. 